\title{
STUDENTS EXPERIENCES ON THE USE OF GOOGLE CLASSROOM: CASE STUDY OF A UNIVERSITY IN RWANDA
}

\author{
Ayodele Ogegbo ${ }^{1}, \&$ Oyebimpe Adegoke ${ }^{2}$ \\ ${ }^{1}$ Department of Science and Technology Education, University of Johannesburg (South Africa) \\ ${ }^{2}$ School of Education, Mount Kenya University (Rwanda)
}

\begin{abstract}
Google is a popular Web 2.0 tools with many interesting facilities and applications. Like many other Web 2.0 tools, Google classroom has potential for teaching and learning due to its unique built-in functions that offer pedagogical, social and technological affordances. With this in mind, Google classroom as an open-source learning platform created in 2015 to simplify and enhance user collaboration, was considered a prominent technology tool used to enhance teaching and learning at a particular University in Rwanda. This study adopts a quantitative descriptive design to investigate university students' Google classroom experiences in Rwanda after participating in an online STEM education course. Data were collected using questionnaires sent to students via a Google form link. The collected data were analyzed using frequency and descriptive analysis. The study has generally confirmed that students have a positive cognitive, affective, and behavioural attitude towards Google classroom use. The study also revealed immediate feedback, accessibility, user-friendliness, collaboration, effective and efficient communication as positive experiences recognized by students using Google classroom in their online STEM education course. Nevertheless, students faced problems such as poor internet connection, lack of technology to access the classroom, insufficient time to submit tasks, lecturers inadequate and untimely response to students' questions, isolated learning, poor knowledge about the user interface, inadequate skills on how to use the classroom. To further encourage the use of google classroom particularly as a learning management system in Rwandan universities and other universities across Africa, findings from this study recommends that education institutions provide students and lecturers with adequate training and platform on how to use the google classroom interface, improve ICT infrastructures, lecturers' use of video chat or asynchronous mode to provide adequate and timely feedback to students within stipulated virtual office hours, ensure quality course content.
\end{abstract}

Keywords: Google classroom, online learning, Rwandan university, STEM course, students experiences.

\section{Introduction}

The introduction of Information Communication Technologies (ICTs) in education continues to change the way schools and universities across the globe embrace technological systems to redefine teaching and learning in the $21^{\text {st }}$ century. However, the Rwandan educational sector policy emphasises the synergistic adoption of ICTs in education as a strategic lever for achieving social and economic transformation after the 1994 genocide that devastated the country's economy and education system (Republic of Rwanda Ministry of Education, 2016; Twagilimana \& Mannikko-Barbutiu, 2018). As part of the transition mechanisms aimed to transform the delivery and quality of education in Rwanda, some institutions of higher learning have adopted various technological equipment, tools and learning management systems including Sakai, Blackboard, Moodle, and Microsoft Teams to promote online social learning environment through distance education, open online courses and/or blended learning (Darius, 2020; Harerimana \& Mtshali, 2018). However, the use of such learning management systems seems to pose several challenges for many university students in the country. In the setting of this inquiry, one of the challenges faced by students was learner isolation. This was due to the fact that the learning management system adopted by the university served a vast population of students from other campuses of the same university. For instance, students located in Kenya, Burundi, and Uganda all accessed the same platform for learning. Additionally, lecturers who handled courses for the face-to-face sessions were different from lecturers who handle the online sessions on the university's Learning Management System platform. Hence, students felt alienated, and found it difficult to participate actively or interact with lecturers as expected. This predicament calls for lecturers and researchers to explore the potential of other web-based technologies to fit the best classroom practice, promote active learning and improve skills development of university 
students. Hence, the university campus in Rwanda took steps to explore Google Classroom as an alternative learning platform. Google is a popular Web 2.0 tools with many interesting facilities and applications developed for academic institutions whose purpose is to facilitate, create, distribute and grade assignments in a paperless way (Sukmawati \& Nensia, 2019). Like many other Web 2.0 tools, Google classroom has potential for teaching and learning due to its unique built-in functions that offer pedagogical, social and technological affordances. Google classroom has shown to be more beneficial compared to other leaning management systems because it is accessible as a free mobile app, easy to use, reliable and provides a platform for network community with a slight resemblance to Facebook user interface (Jordan \& Duckett, 2018). However, Pappas (2015) asserts that not all learning courses are suitable using Google Classroom because it has difficult account management, limited integration options, no automated updates, difficult learner sharing, editing problems, no automated quizzes and test. Given the need to harness the affordances of free and user friendly technological applications to promote a knowledge based society within the broader Rwandan educational context, this study explored the experiences of students on the use of google classroom as a learning tool in a science education course offered at a university in Rwanda. In this study, understanding students' attitudes towards the use of google classroom also provided meaningful insights into their experiences. Thus, this study is guided by the following research questions:

- What are the opinions of students' regarding their experiences on the use of Google classroom as a learning tool in a university in Rwanda?

- What are the attitudes of students regarding the use of Google classroom?

\section{Research design and methodology}

A quantitative research design located within the descriptive research paradigm was adopted in this study. The quantitative design was appropriate for this study as it provides the fundamental connection between empirical observation and mathematical expression of quantitative relationships that allows the use of statistical procedures and the principles of objectivity (Queirós, Faria, \& Almeida, 2017). Data was collected through survey questionnaires created electronically using Google forms and the link was sent to undergraduate students that participated in the blended learning course education technology at a university in Kigali, Faculty of Education. However, a total of seventy-one (71) students consisting 25 females $(35.2 \%)$ and 46 males $(64.8 \%)$ responded to the questionnaire. The questionnaire consisted of three open-ended questions and 26 items to which students could rate their agreement or disagreement via Likert scale: Strongly Disagree $=\mathrm{SD}$, Disagree $=\mathrm{DA}$, Neutral $=\mathrm{N}$, Agree $=$ A, and Strongly Agree $=$ SA. Analysis of data was guided by the use of percentage and frequency distribution.

\section{Findings}

Results from participants responses showed that the questionnaire has a high internal consistency with a Cronbach alpha value of 0.953 . From the responses of students, their experiences were expressed based on their opinion and attitude towards using google classroom.

Figure 1. Usage of Google classroom.

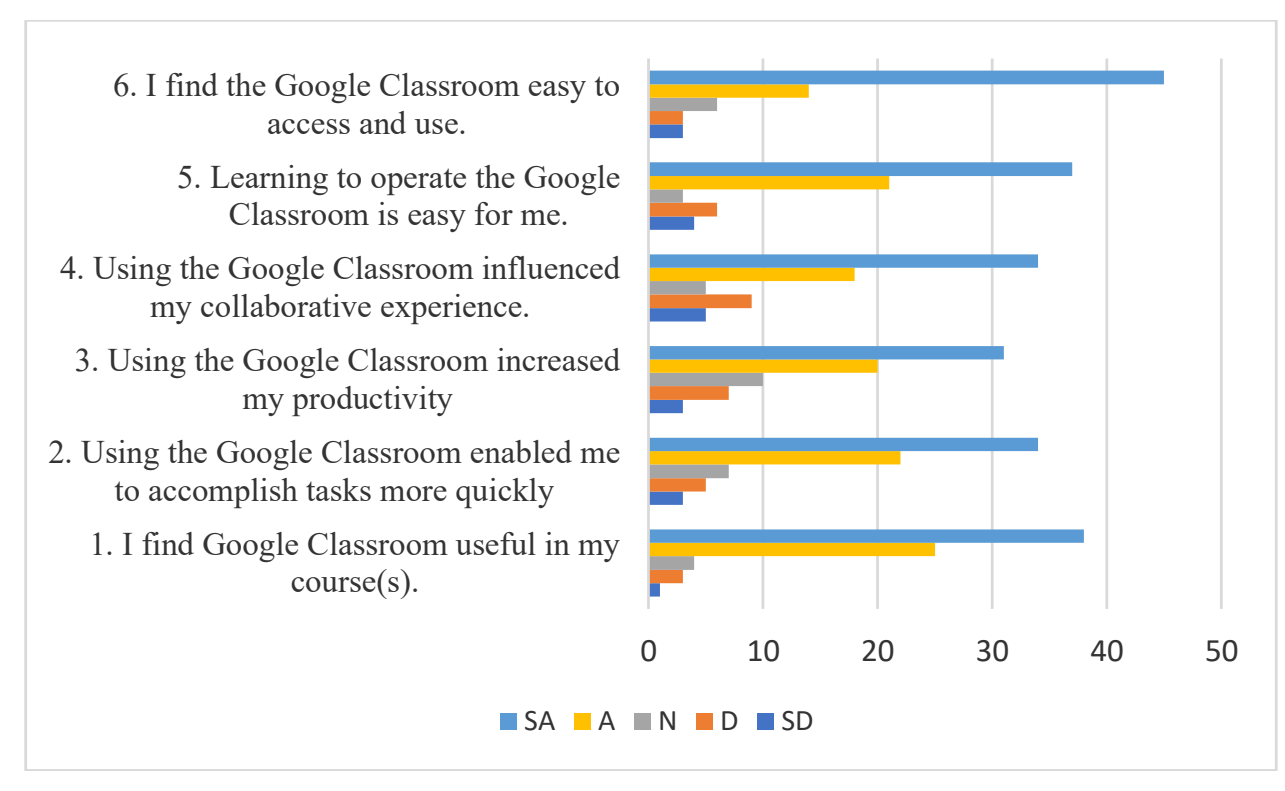


Figure 1 shows that $63.4 \%$ of the students strongly agreed that google classroom was easy for them to access and $52.1 \%$ indicated that google classroom was easy for them to navigate. Students ease of access was further explained in the open-ended questions using statements such as "easy to submit assignment, log in, receive course materials, navigate the icons in the google classroom application”. Similarly, 47.9\% of them strongly agreed that using google classroom influenced their collaborative experience with colleagues and enabled them to accomplish tasks more quickly. More so, during the analysis of the open-ended question that required students to share their experiences, $30 \%$ of the students indicated time management as one the benefits of using google classroom using statements such as "it saves time, it helps me to submit assignment on time, I am able to get information about the course and material on time". Findings from the survey also reveal that students experiences regarding the use of Google classroom was viewed based on challenges they encounter while using the technology application as shown in figure 2.

Figure 2. Challenges encountered while using Google classroom.

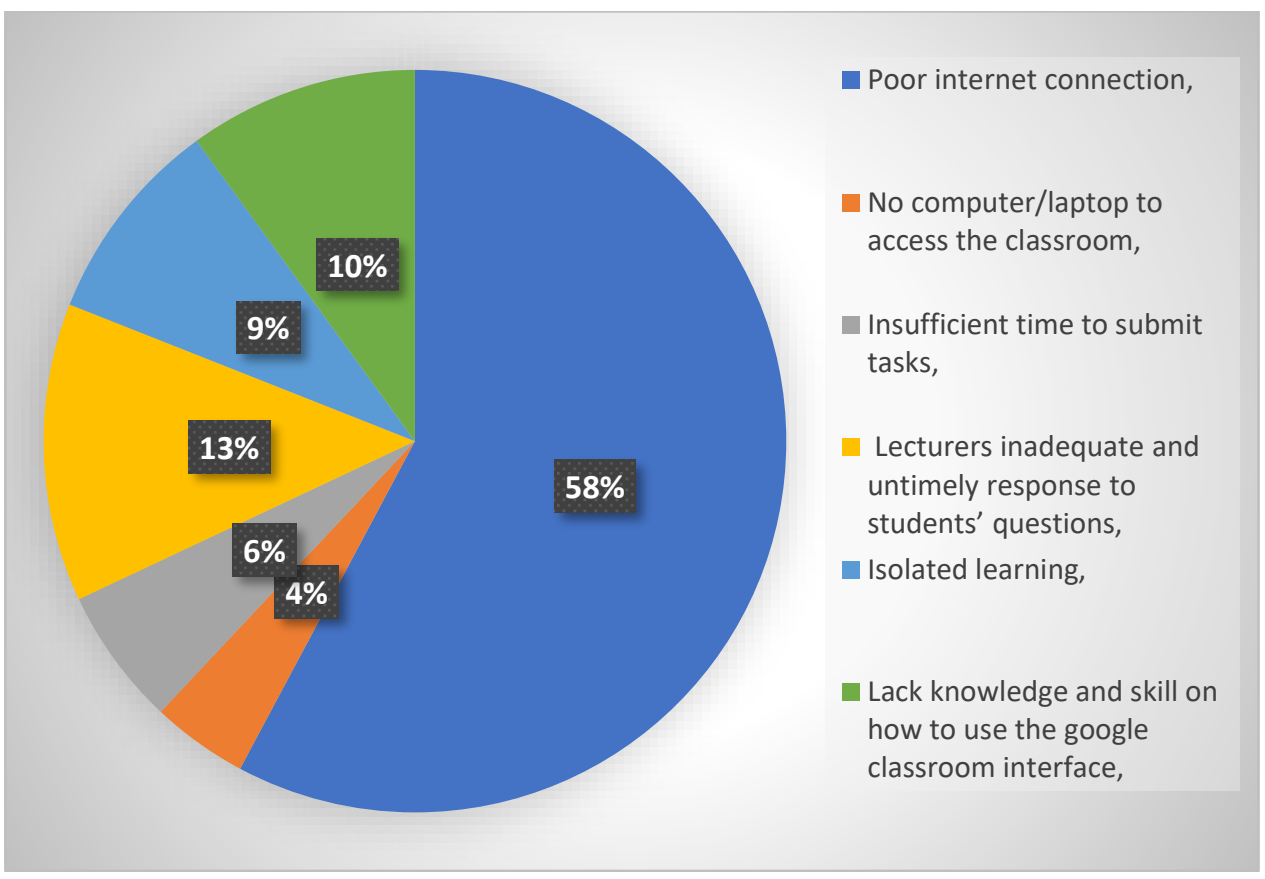

As reflected in Figure 2 above, a vast majority of the students mentioned poor internet connection as the major challenge encountered when using google classroom. $13 \%$ of the students claimed that when they submit assignments using google classroom lecturers sometimes do not grade the assignment neither do the give clear and adequate feedback to students, lecturers also do not explain content in details. More so, $10 \%$ of the students indicated that they do not have the knowledge or skills to use the google classroom application. Another challenge encountered as indicated by students include a feeling of isolated learning where students stated that they get bored using google classroom because they lack physical contact with colleagues. In addition, students' experiences were also reported based on their attitude towards the use of google classroom as shown in Table 1.

Table 1. Students experiences relating to attitudes.

\begin{tabular}{|l|l|l|l|l|l|}
\hline Statements on student experiences related to & \multicolumn{5}{|c|}{ Distribution of students' responses } \\
\cline { 2 - 5 } their attitude & SD & D & N & A & SA \\
\hline $\begin{array}{l}\text { I have the knowledge necessary to participate in } \\
\text { Google Classroom. }\end{array}$ & $4.2 \%$ & $8.5 \%$ & $12.7 \%$ & $25.4 \%$ & $49.3 \%$ \\
\hline $\begin{array}{l}\text { Participating in Google Classroom makes me } \\
\text { engage more in learning }\end{array}$ & $15.5 \%$ & $18.3 \%$ & $16.9 \%$ & $29.6 \%$ & $19.7 \%$ \\
\hline $\begin{array}{l}\text { I can get help from others when I have difficulties } \\
\text { participating in Google Classroom. }\end{array}$ & $4.2 \%$ & $9.9 \%$ & $4.2 \%$ & $29.6 \%$ & $52.1 \%$ \\
\hline $\begin{array}{l}\text { I feel excited about using Google classroom } \\
\text { I like using Google Classroom compared to face to } \\
\text { face (offline) classes or other LMS. }\end{array}$ & $7.0 \%$ & $9.9 \%$ & $15.5 \%$ & $28.2 \%$ & $39.4 \%$ \\
\hline
\end{tabular}


Table 1 above showed the percentage distribution of students responses to the attitude developed as a result of their experience using google classroom. Results indicates that majority of the students strongly agreed or agreed with each of the statements concerning their attitude towards the use of google classroom. Thus implying that most of the students appear to have a favourable cognitive, behavioural and affective attitude towards the use of Google classroom. However, further analysis of participants responses to the questionnaire revealed that $45.1 \%$ of the students rarely use google classroom but would like to learn more, $21.1 \%$ of the students occasionally use google classroom and would like to learn more, $9.9 \%$ of the students use google classroom almost every time but do not like to use it within the classroom while $23.9 \%$ of the students use google classroom every time and extremely well.

\section{Discussion and conclusion}

The present study was designed to investigate students' experiences regarding the use of Google Classroom for online learning in a University in Rwanda. In the process, the study also uncovered the attitude of students towards the use of google classroom. The study provided evidence that majority of the students recognise the benefits of using google classroom such as easy to access and navigation of the google classroom platform compared to other learning management system, easy access to course materials, enhancing their ability to collaborate and share information with colleagues, enhances their knowledge as well as improves their ability to be well acquainted with the use of technology and e-learning platforms, creating effective and efficient communication with colleagues and lecturer during the online STEM education course. It was also found that students demonstrated a positive cognitive, behavioural, and affective attitude towards using Google classroom. These results echoed previous research (e.g. Islam, 2019; Khalil, 2018).

Findings also show that a number of challenges were mentioned by the students which is better to be addressed by the various educational stakeholders, Government and Higher institutions authorities as well as lecturers. For instance, despite students' positive experience while using google classroom in Rwanda, many of them struggle to log into the class because they are in areas where internet connection is bad, and some have to share laptops /computers with others. This implies that the most common challenge faced by the students is their lack of access to technological resources. More so, some of the students mentioned that they do not have the adequate knowledge on how to use Google classroom thereby indicating their lack of technological knowledge. Whereas some of the students mentioned that they do not receive optimal feedback from the lecturer and communicating privately with lecturer and/or colleagues appears impossible, thus supporting the findings of Islam (2019). More so, a lower percentage of the students indicated that using google classroom did not provide them the critical human interaction and engagement required to make learning fun and as a result learning becomes too serious and boring.

It is suggested that institutions of higher learning in Rwanda and other African countries encourage the adoption of Google classroom as a learning management platform that can help facilitate online learning experiences for students, foster pedagogical and positive attitude towards the use of technology outside the classroom. In addition, there is a crucial need for Government and higher education institutions to facilitate the promotion and provision of better ICT infrastructures such as computer, laptops, and internet connectivity in order to make access to google classroom and other innovative instructional platform easier for students. Adequate training on how to leverage Google classroom for successful teaching and learning experience should also be provided to lecturers and students. This will allow lecturers to ensure quality content for their course and using video chat or asynchronous mode to provide students with adequate and timely feedback within specified virtual office hours.

\section{References}

Darius, (2020). University of Rwanda online learning at a glance: what you need to know about the platform. Retrieved from https://ur.ac.rw/?UR-online-learning-at-a-glance-what-you-need-to-knowabout-the-platform

Harerimana, A., \& Mtshali, N. G. (2018). Implementing e-learning in resource-constrained nursing education institutions in Rwanda. Research and Reviews: Journal of Nursing and Health Sciences, 4, 1-14.

Islam, M. S. (2019). Bangladeshi University Students' perception about using Google Classroom for Teaching English. International Journal of Psycho- Educational Sciences, 8(2), 57 - 65.

Jordan, M. M., \& Duckett, N. D. (2018). Universities confront 'tech disruption': Perceptions of student engagement online using two learning management systems universities confront 'tech disruption': Perceptions of student. The Journal of Public and Professional Sociology, 10(1) 
Khalil, Z. M. (2018). EFL Students' Perceptions towards Using Google Docs and Google Classroom as Online Collaborative Tools in Learning Grammar. Applied Linguistics Research Journal, 2(2), 33-48.

Pappas, C, (2015). Google Classroom Review: Pros and Cons of Using Google Classroom In eLearning. Retrieved from https://elearningindustry.com/google-classroom-review-pros-and-cons-of-usinggoogle-classroom-in-elearning

Queirós, A., Faria, D., \& Almeida, F. (2017). Strengths and limitations of qualitative and quantitative research methods. European Journal of Education Studies, 3 (9), 369-387. doi: $10.5281 /$ zenodo. 887089

Republic of Rwanda Ministry of Education (2016). ICT in education ploicy. Retrieved from http://planipolis.iiep.unesco.org/sites/planipolis/files/ressources/rwanda_ict_in_education_policy_a pproved.pdf

Sukmawati, S., \& Nensia, N. (2019). The Role of Google Classroom in ELT. International Journal for Educational and Vocational Studies, 1(2), 142-145.

Twagilimana, I., \& Mannikko-Barbutiu, S. (2018, June). ICT in education policy in Rwanda: current situation, challenges and prospects. In ACRID 2017: EAI International Conference for Research, Innovation and Development for Africa (p. 360). European Alliance for Innovation. 